\title{
Evaluating canopy transpiration and water use of two typical planted tree species in the dryland Loess Plateau of China
}

\author{
Handan Zhang ${ }^{1,2}$ | Wei Wei ${ }^{1}$ (D) | Liding Chen ${ }^{1}$ | Lei Yang ${ }^{1}$
}

\author{
${ }^{1}$ State Key Laboratory of Urban and Regional \\ Ecology, Research Center for \\ Eco-Environmental Sciences, Chinese \\ Academy of Sciences, Beijing 100085, China \\ ${ }^{2}$ University of Chinese Academy of Sciences, \\ Beijing 100049, China \\ Correspondence \\ Wei Wei, State Key Laboratory of Urban and \\ Regional Ecology, Research Center for \\ Eco-Environmental Sciences, Chinese \\ Academy of Sciences, Beijing 100085, China. \\ Email: weiwei@rcees.ac.cn \\ Funding information \\ National Natural Science Foundation of China, \\ Grant/Award Number: 41371123, 41390462 \\ and 41401209, National Key Research and \\ Development Program of China, Grant/Award \\ Number: 2016YFC0501701, and the National \\ Advanced Project of the Twelfth Five-year \\ Plan of China, Grant/Award Number: \\ 2015BAC01B02
}

\begin{abstract}
Large-scale vegetation restoration has been conducted in China's Loess Plateau over the past several decades to control soil and water loss. However, these efforts have not followed any specific guidelines to select plant species that balance the twin goals of vegetation restoration and water demand. In the present study, we measured canopy transpiration characteristics of oriental arborvitae (Platycladus orientalis) and Chinese pine (Pinus tabulaeformis), two species that are commonly planted in restoration efforts, and recorded water input and output for these two species during the growing season. P. tabulaeformis had a higher tolerance than P. orientalis to warmer and drier environments and used water over a wider time span. Canopy transpiration significantly increased when rainfall exceeded $15 \mathrm{~mm}$ and was negatively correlated with net change of soil water content. Meanwhile, rainless intervals also affected canopy transpiration recovery. Canopy transpiration of $P$. tabulaeformis was $25.4 \%$ higher than that of $P$. orientalis. Soil water content under $P$. orientalis declined by $28.4 \%$ after the growing season, while it slightly increased under P. tabulaeformis (0.7\%). Our results suggested that although P. tabulaeformis plantation had higher canopy transpiration, this water use did not drastically reduce soil water content, mainly due to the lower evaporation caused by the dense canopy cover. However, the low soil water content also implied that a better management, such as a mixed plantation of these two species and other supplemental water-conservation techniques, should be considered to better use water in this semiarid region.
\end{abstract}

\section{KEYWORDS}

canopy transpiration, Loess Plateau, sap flow, soil water, water budget

\section{1 | INTRODUCTION}

Tree transpiration plays an important role in the water balance of forests and has significant influence on water yields (Chang, et al., 2014a). It can be regulated by a series of ecological factors, such as competition for water among different species and the ability of plants to "bioengineer" the soils that they occupy, and physiological factors that affect the delivery of water to the leaf surface (Mitchell, Veneklaas, Lambers, \& Burgess, 2009). Understanding water use by trees is crucial for sustainable ecological restoration, especially in arid and semiarid regions where water availability is the primary limiting factor for tree survival and stand development (Chen et al., 2014a).

Previous studies indicate that precipitation and soil water condition have an integrated influence on plant water use (Chen et al., 2014a; Chen et al., 2014b; Zhao \& Liu, 2010), and climate conditions influence transpiration demands (Caldeira et al., 2015;
Zhang, He, Burnham, \& Zhang, 2016; Zheng \& Wang, 2014). The conceptual "threshold-delay" model, proposed by Ogle and Reynolds (2004), has been used to determine the threshold of rainfall pulses that initiate sap flow (SF) responses in shrubs (Zhao \& Liu, 2010) and woodlands (Zeppel, Macinnis-Ng, Ford, \& Eamus, 2008). Generally, the threshold differs by species and areas, mainly due to the differences in climate conditions and edaphic properties (Chen et al., 2014a; Du et al., 2011). Under dry conditions, soils usually experience a water deficit, and the rainfall pulses remain below some critical thresholds. Lower thresholds may just meet the need for surface moistening or evaporation, without affecting the SF. If the pulse is greater than the lowest threshold, it triggers the plant's response (Ogle $\&$ Reynolds, 2004). The balance of soil water between replenishment (e.g., precipitation) and extraction (e.g., evaporation and transpiration) affects the influence of rainfall over subsequent transpiration during the later rainless intervals (Chen et al., 2014a; Chen et al., 2014b). 
For Qinhai spruce, Chang, Zhao, and He (2014b) established a logistic function between SF and soil moisture content that explained $84 \%$ of the variations in SF velocity. Shen, Gao, Fu, and Lü (2015) showed that sufficient recharge of soil water can significantly accelerate stand transpiration. At an annual temporal scale, stand transpiration showed a positive relationship with soil water content (SWC; Zhang, Guan, Shi, Yamanaka, \& Du, 2015).

Meanwhile, the response of plant water use to precipitation and soil water conditions is associated with stomatal control (Chen et al., 2015; de Dios et al., 2014). Stomatal closure is the main mechanism that regulates transpiration, avoiding irreversible damage to plant hydraulic systems (Gotsch et al., 2014). Hysteresis is one of the most obvious phenomena related to plant transpiration that has been examined as a function of micrometeorological variables (RodriguezDominguez et al., 2012; Zheng \& Wang, 2014). The hysteresis between $S F$ and vapor pressure deficit occurred in a clockwise manner, while the hysteresis between SF and photosynthetic photon flux density changed from counterclockwise (after precipitation) to clockwise (under dry conditions; Zheng \& Wang, 2014). Besides, plant transpiration shows species-specific responses to variation in microclimatic and soil water conditions (Chirino, Bellot, \& Sanchez, 2011; Du et al., 2011). For example, in drought-prone regions, intermittent water availability threatens the survival rates of woodland trees (Chen et al., 2014a). In the semiarid Mediterranean region, Pinus halepensis, Pistacia lentiscus, and Erica multiflora show water-saving mechanisms to cope with drought, while Quercus coccifera and Stipa tenacissima show water-spending mechanisms (Chirino et al., 2011). In the semiarid Loess Plateau of China, the exotic Robinia pseudoacacia was defined as a drought-sensitive type, and the naturally dominant Quercus liaotungensis and the indigenous concomitant species, Armeniaca sibirica, were defined as drought-insensitive types (Du et al., 2011). Compared with Eucalyptus melliodora and Eucalyptus polybractea, Eucalyptus cladocalyx could better tolerate saline soils, hot weather, and periods of drought, and it was determined to be the best-suited species to meet the goals of a phytoremediation project at a mine site (Doronila \& Forster, 2015). Obviously, monitoring tree transpiration characteristics is essential in phytoremediation and can have key implications for plant species selection and management.

The semiarid Loess Plateau in China has experienced severe soil erosion, vegetation degradation, and desertification for centuries ( $\mathrm{Fu}$ et al., 2006). Since the 1970 s, vegetation restoration practices (i.e., planting trees and perennial shrubs) have been carried out to improve the environmental quality and to reduce water and soil losses (Chen, Wang, Wei, Fu, \& Wu, 2010). However, several researchers have reported that soils become extremely dry in both deep and shallow layers after large-scale vegetation restoration (Yang, Wei, Chen, Chen, \& Wang, 2014). Because it causes soil desiccation, the initially promoted afforestation has not had the positive effect on the landscape that it was intended to have (Liu et al., 2010; Rodríguez-Caballero, Cantón, Chamizo, Afana, \& Solé-Benet, 2012); indeed, it has resulted in vegetation deterioration and difficulties in natural regeneration (Chen, Shao, \& Li, 2008; Yang et al., 2014), fluctuations in agricultural crop production (Wang, Muhammad, Hao, \& Li, 2011a), and unfavorable provision of ecosystem services (Yang, Chen, \& Wei, 2015; Zhang, $\mathrm{He}$, et al., 2016). Consequently, a better understanding of the water use characteristics of different planted species is necessary for sustainable ecological restoration in the dryland Loess Plateau and other water-limited regions.

This study focused on a small catchment in the western Chinese Loess Plateau, where we compared the transpiration characteristics of two typical tree species that are commonly planted in the area, Pinus tabulaeformis and Platycladus orientalis, and evaluated their water budgets during the growing season. Specifically, we examined the soil water changes of both sites during the growing season. The results are expected to provide insights into plant water use strategies, species selection, and sustainable forest managements.

\section{2 | MATERIALS AND METHODS}

\section{1 | Site description}

The study area was located in Longtan watershed in Gansu Province, in the western part of the Loess Plateau in China $\left(35^{\circ} 43^{\prime}-35^{\circ} 46^{\prime} \mathrm{N}\right.$ and $104^{\circ} 27^{\prime}-104^{\circ} 31^{\prime} \mathrm{E}$ ). The study site is a typical hilly region with gullies and elevations ranging from 1,937 to $2,151 \mathrm{~m}$. The area is located in a semiarid temperate zone with an annual mean temperature of $6.8^{\circ} \mathrm{C}$ and annual mean precipitation of $386 \mathrm{~mm}$. Most rainfall occurs during the summer months, from July to September, in the form of thunderstorms. The mean annual potential evapotranspiration is about $1,649 \mathrm{~mm}$. These annual averages were derived from meteorological data provided by a meteorological station located $0.6 \mathrm{~km}$ from the watershed and represent the averages of 45 years (1961-2006; Yang et al., 2015).

Soil types in the study area are mainly composed of loess soil with low fertility and are vulnerable to soil erosion. Soil thickness varies from 40 to $60 \mathrm{~m}$. The texture is composed of a loose structure, with a high silt content (ca. $81 \%$ ), a soil moisture field capacity of $0.180-0.240 \mathrm{~g} / \mathrm{g}$, a saturated moisture content of about $0.470 \mathrm{~g} / \mathrm{g}$, and little organic matter (ca. 0.2-2.9\%).

With the implementation of the "Grain for Green" project, Chinese pine (P. tabulaeformis Carr.), oriental arborvitae ( $P$. orientalis), purple alfalfa (Medicago sativa), and korshinsk peashrub (Caragana korshinskii) were widely planted. Land-cover patterns in the study area can be classified into abandoned cropland, arable land, native grassland, artificial grassland, shrubland, and tree plantations.

\subsection{Experimental design and data collection}

\subsection{1 | Experimental design}

Two experimental plots (10 m length $\times 10 \mathrm{~m}$ width), in the middle of east-facing slopes, were selected for comparison, one planted with P. orientalis in 1984 and the other planted with P. tabulaeformis in 1972 (Figure 1). Each plot was bordered with a steel fence about $20 \mathrm{~cm}$ high and an outer fence about $1.5 \mathrm{~m}$ high surrounded the plot in order to prevent anthropogenic disturbances. Through tree, surveys were conducted before the growing season. For each plot, eight individual trees with different diameters at breast height $(\mathrm{DBH}, \mathrm{cm})$ were selected for the SF measurement. Detailed information regarding tree samples is shown in Table 1. SF, SWC, and meteorological data were monitored from April 27 to October 1, 2015. 

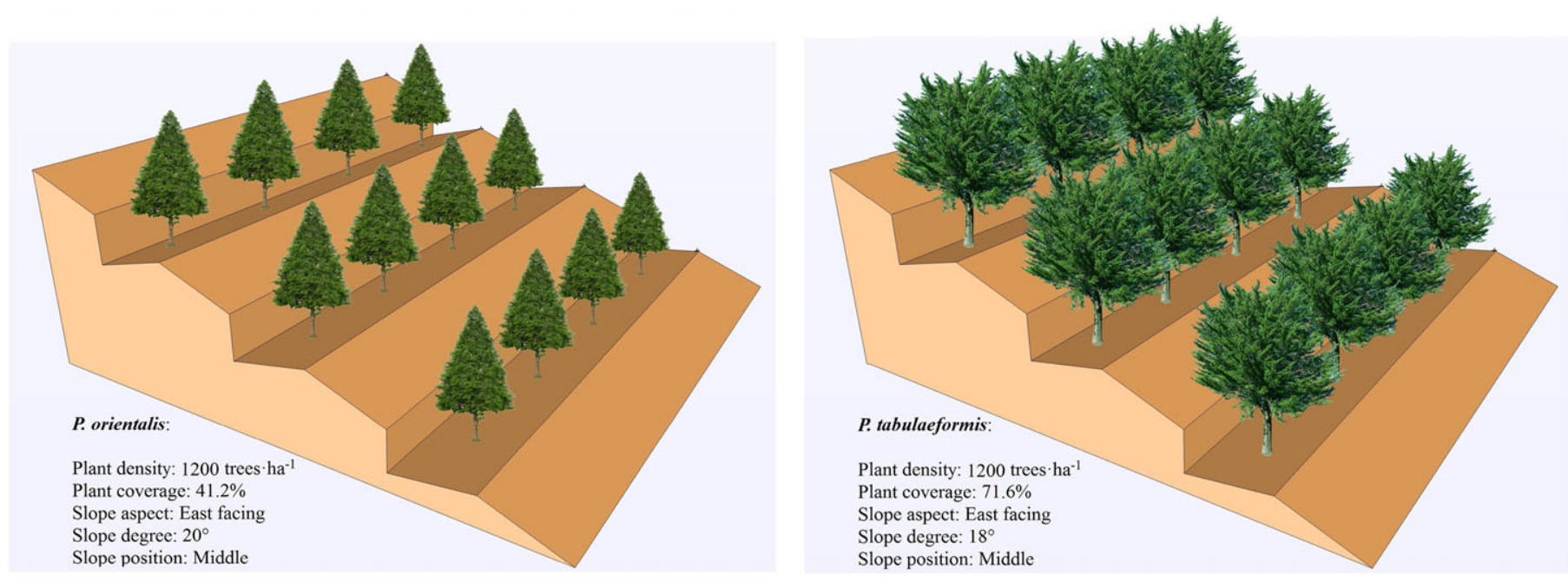

FIGURE 1 Sketch map and information of the Platycladus orientalis plantation (left) and Pinus tabulaeformis plantation (right)

\subsection{2 | SF measurement}

SF was measured at 10-s intervals with constant heat flow gauges using the Granier type thermal dissipation sensor (TDP5, TDP10, Rain Root Scientific Limited Company, Beijing, China). An average value for the SF measurements spanning 10 min was recorded. SF density was calculated according to standard calibration for the TDP method based on temperature differences between two probes (Granier, 1987):

$$
J_{\mathrm{s}}=0.0119 *\left[\left(\Delta T_{\max }-\Delta T\right) / \Delta T\right]^{1.231}
$$

where $J_{s}$ is SF density $\left(\mathrm{g} \mathrm{m}^{-2} \mathrm{~s}^{-1}\right), \Delta T_{\max }$ is the maximum temperature difference with zero $S F$ assumed $\left({ }^{\circ} \mathrm{C}\right)$, and $\Delta T$ is the temperature difference between sensors at any given time $\left({ }^{\circ} \mathrm{C}\right)$.

SF $\left(\mathrm{kg} \mathrm{day}^{-1}\right)$ was derived from the product of the SF density by the sapwood area $\left(A_{s}, \mathrm{~cm}^{2}\right)$, based on the assumption of a uniform radial SF profile (Chang et al., 2014a). It was calculated as

$$
S F=86.4 J_{s} A_{s} / 10,000
$$

Canopy transpiration $\left(T_{c}, \mathrm{~mm}\right.$ day $\left.^{-1}\right)$ was obtained from the $S F$ and crown projected area $\left(A_{c}, m^{2}\right)$ (Shen et al., 2015) as

$$
T_{c}=S F / A_{c}
$$

\subsection{3 | Environmental variables}

Meteorological data, including solar radiation $\left(R_{a}\right)$, air temperature $(T)$, relative humidity $(R H)$, wind speed $\left(W_{s}\right)$, atmospheric pressure $\left(P_{a}\right)$, and precipitation $(P)$, were measured continuously with an automatic weather station Vantage Pro2 (Davis Company, USA). All measurements were taken at 10-s intervals and averaged every hour. Vapor pressure deficit (VPD) was calculated from $T$ and $R H$ data.
SWC was monitored continuously using HOBO U30 (Onset Computer Corporation, Bourne, USA). Each instrument included seven probes set to depths of $10,20,30,40,60,80$, and $100 \mathrm{~cm}$, respectively. The net change in SWC $(\triangle S W C)$ was given as $\triangle S W C=S W C_{2}-S W C_{1}$, where $S W C_{1}$ was the antecedent $S W C$ and $S W C_{2}$ was the SWC at a certain time. The SWC monitored in late April was considered the antecedent SWC.

\section{3 | Data analysis}

$T_{c}$ data were converted to an average value per hour to analyze the trend with meteorological factors, and the daily maximum and the corresponding $R_{a}, V P D$, and $T$ were selected to calculate the optimal values. Student $t$ test was used to determine significant differences between species regarding the daily maximum and daily average. Linear regression analysis was used to assess the trends of daily transpiration versus $\triangle S W C$, with significance set at $p<.05$. To evaluate the water budget variation for both sites, we assessed monthly precipitation, transpiration, evaporation, and net changes of SWC. Statistical analyses were run using the SPSS version 17.0 software (SPSS Inc., Chicago, IL, USA). Plotting and curve fitting were performed using the OriginPro Version 8.0 software (OriginLab Corporation, USA).

\section{3 | RESULTS}

\subsection{Daily variation in $T_{c}$}

The diurnal variations of $T_{c}$ of $P$. orientalis and $P$. tabulaeformis followed a similar trend, with higher values in daytime and lower values at night, but they did not reach zero (Figure 2). Both species showed an obvious night SF. The diurnal course of $T_{c}$ was closely related to changes in

TABLE 1 Characteristics of sample trees (mean \pm standard deviation)

\begin{tabular}{lcccc} 
Species & DBH $(\mathrm{m})$ & Sapwood area $\left(\boldsymbol{A}_{s}, \mathrm{~cm}^{2}\right)$ & Crown area $\left(\mathrm{m}^{2}\right)$ & Height $(\mathrm{m})$ \\
\hline Platycladus orientalis & $5.05^{\mathrm{a}} \pm 1.28$ & $18.13^{\mathrm{a}} \pm 8.28$ & $3.51^{\mathrm{a}} \pm 0.47$ & $3.33^{\mathrm{a}} \pm 0.82$ \\
Pinus tabulaeformis & $9.44^{\mathrm{b}} \pm 1.29$ & $52.96^{\mathrm{b}} \pm 13.64$ & $5.89^{\mathrm{b}} \pm 0.89$
\end{tabular}

Note. $\mathrm{DBH}=$ diameter at breast height. Significant differences between species are indicated by superscript letters. 
solar radiation and vapor pressure deficit. The maximum value of $T_{c}$ of $P$. orientalis occurred earlier (10:00-11:00 hr) than the maximum values of $R_{a}(13: 00-14: 00 \mathrm{hr})$ and VPD (14:00-16:00 hr), and the maximum value of $T_{c}$ of $P$. tabulaeformis was observed concurrently with the maximum value of $R_{a}$ but occurred slightly earlier than the maximum value of VPD.

During the growing period, $P$. orientalis had a significantly higher maximum SF density $\left(J_{s, \max }\right)$ than did P. tabulaeformis (Table 2$)$. The optimal meteorological variations for both species are presented in Table 2. For $P$. orientalis, $J_{s}$ reached the maximum under a relatively mild climate, with $R_{a}$ of $517.6 \pm 205.1 \mathrm{~W} \mathrm{~m}^{-2}$, VPD of $0.9 \pm 0.4 \mathrm{kPa}$, and $T$ of $18.2 \pm 3.8{ }^{\circ} \mathrm{C}$, and the corresponding climate for $P$. tabulaeformis to reach $J_{s, ~} \max$ was much higher, with $R_{a}$ of $649.0 \pm 259.5 \mathrm{~W} \mathrm{~m}^{-2}, \mathrm{VPD}$ of $1.6 \pm 0.7 \mathrm{kPa}$, and $T$ of $21.3 \pm 4.6{ }^{\circ} \mathrm{C}$. Student $t$ test showed that these differences between the two tree species were significant.

\subsection{Influence of rainfall on transpiration}

During the experimental period, 60 rainfall events were recorded, ranging from 0.2 to $38.4 \mathrm{~mm}$, with a total rainfall depth of $295.6 \mathrm{~mm}$. Most of the rainfall events were small, and the majority (73.4\%) were less than $5 \mathrm{~mm}$ (Table 3). As rainfall amounts increased, rainfall frequency decreased. However, the larger events (>15 mm) accounted for $52.0 \%$ of the total precipitation amount.

Figure 3 shows the $T_{c}$ between pre- and post-rainfall periods in different rainfall sizes. Post-rainfall $T_{c}$ was slightly higher than pre-rainfall transpiration, and was significantly different when rainfall depths exceeded $15 \mathrm{~mm}$. For each pre- and post-rainfall $T_{c}$ value, no significant differences were observed among rainfall sizes. $P$. orientalis and $P$. tabulaeformis showed different time lags in their responses to rainfall pulses. $P$. orientalis reached the maximum $T_{c}$ the second day after rainfall, and the maximum $T_{c}$ of $P$. tabulaeformis occurred about 2 days later (Figure 4).

\subsection{Correlation between $T_{c}$ and net change in SWC}

We examined the relationship between $T_{c}$ and $\triangle S W C$. $T_{c}$ of $P$. orientalis and $P$. tabulaeformis were negatively correlated with a wide range of $\triangle S W C$ (Figure 5). During the study period, $77.5 \%$ and $64.3 \%$ of the $T_{c}$ of $P$. orientalis and $P$. tabulaeformis, respectively, occurred in a water deficit $(\triangle S W C<0$; Figure 5$)$. This observation is supported by Figure 6, which shows that mean SWC of $P$. orientalis site declined from $11.86 \%$ to $8.49 \%$. In contrast, SWC of P. tabulaeformis showed a slight increase, from $5.77 \%$ to $5.81 \%$ (Figure 6 ).

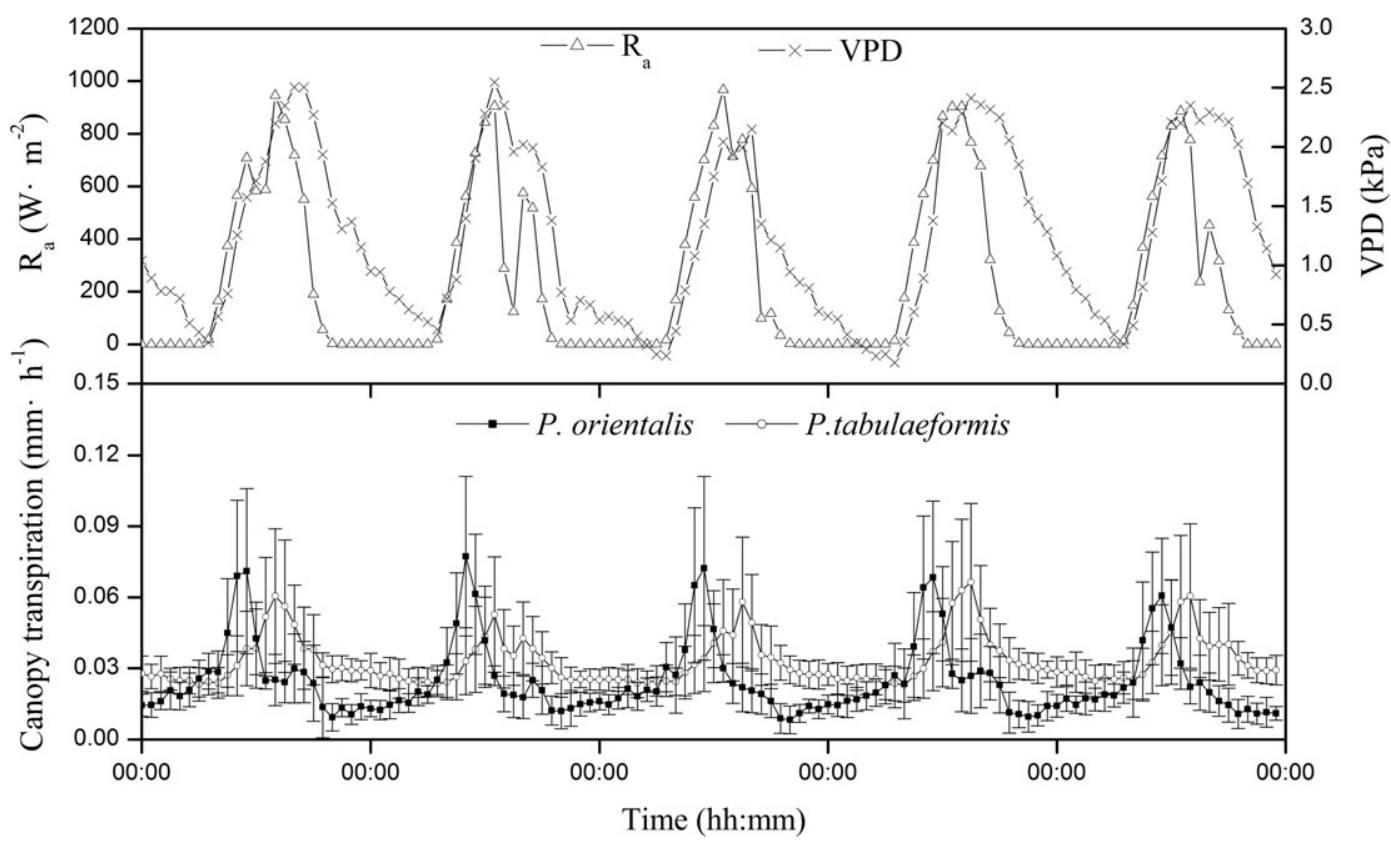

FIGURE 2 Diurnal courses of solar variation $\left(R_{a}\right)$, vapor pressure deficit (VPD), and canopy transpiration $\left(T_{c}\right)$ of two tree species. Data are means \pm standard deviation $(n=8)$

TABLE 2 Diurnal maximum sap flow density $\left(J_{s, \max }\right)$ and key meteorological variables

\begin{tabular}{|c|c|c|c|c|c|}
\hline Species & $J_{s, \max }\left(g \cdot \mathrm{m}^{-2} \cdot \mathrm{s}^{-1}\right)$ & $R_{a}\left(\mathrm{~W} \cdot \mathrm{m}^{-2}\right)$ & VPD (kPa) & $R H(\%)$ & $T\left({ }^{\circ} \mathrm{C}\right)$ \\
\hline Platycladus orientalis & $0.005^{\mathrm{a}} \pm 0.002$ & $517.6^{a} \pm 205.1$ & $0.9^{a} \pm 0.4$ & $57.5^{\mathrm{a}} \pm 15.1$ & $18.2^{a} \pm 3.8$ \\
\hline Pinus tabulaeformis & $0.003^{b} \pm 0.001$ & $649.0^{\mathrm{b}} \pm 259.5$ & $1.6^{\mathrm{b}} \pm 0.7$ & $41.2^{\mathrm{b}} \pm 18.2$ & $21.3^{\mathrm{b}} \pm 4.6$ \\
\hline
\end{tabular}

Note. Mean values without common letters in the same column are significantly different. $J_{s, \max }, R_{a}, \mathrm{VPD}, R H$, and $T$ represent diurnal maximum sap flow density, solar radiation, vapor pressure deficit, relative humidity, and air temperature, respectively. 
TABLE 3 Distribution of rainfall and rainfall events during the study period

\begin{tabular}{lccc} 
Rainfall class $(\mathrm{mm})$ & Frequency $(\%)$ & Rainfall $(\mathrm{mm})$ & Proportion (\%) \\
\hline$<1$ & 31.7 & 9.6 & 3.2 \\
$1-5$ & 41.7 & 59 & 20.0 \\
$5-10$ & 16.6 & 73.2 & 24.8 \\
$>15$ & 10 & 153.8 & 52.0 \\
Total & 100 & 295.6 & 100 \\
\hline
\end{tabular}

\section{4 | Water budget}

The monthly $P, T_{c}$, evaporation (E), and net change in $\triangle S W C$ during the growing season were calculated and the results are presented in Table 4. The total $T_{c}$ of $P$. tabulaeformis was $25.4 \%$ higher than that of $P$. orientalis, and $E$ was $34.0 \%$ higher in $P$. orientalis. The $\triangle S W C$ was negative in most months from May to September, especially in P. orientalis. Water loss exceeded precipitation during these months, a notable situation in this semiarid climate (Jian, Zhao, Fang, \& Yu, 2015a; Yaseef, Yakir, Rotenberg, Schiller, \& Cohen, 2010). $P$. tabulaeformis had a soil water surplus in May, June, and July, while $P$. orientalis had a surplus only in May. During the growing season, $E / P$ accounted for $76.8 \%$ and $57.3 \%$ of $P$. orientalis and $P$. tabulaeformis, respectively.

\section{4 | DISCUSSION}

\subsection{The effect of plant species on $T_{c}$}

Results showed that there was a pronounced diurnal hysteresis between $T_{c}$ and $R_{a}$, and between $T_{c}$ and VPD, and it differed in species (Figure 2). Hysteresis may be viewed as a self-protection strategy for plants that helps them avoid extremely high transpiration rates, thus preventing excessive extraction of water from the stem (Roddy \& Dawson, 2013; Zheng \& Wang, 2014). Species-specific effects,

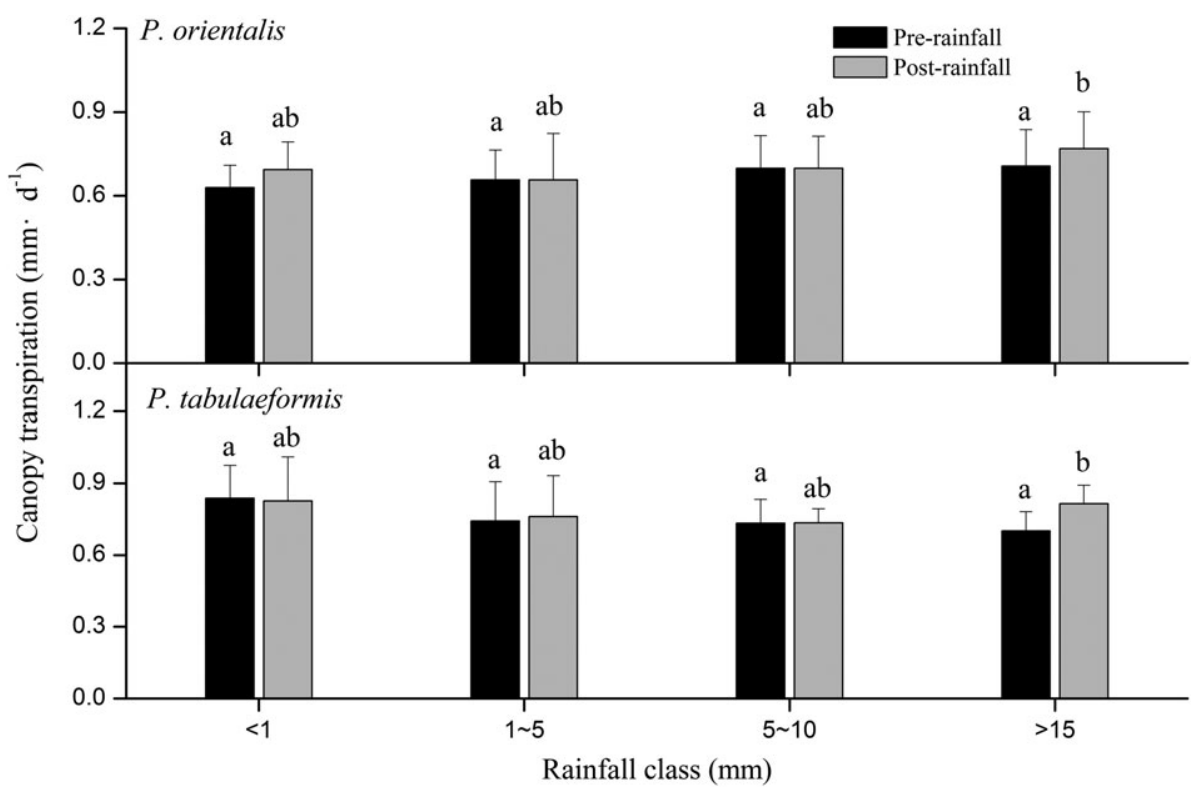

FIGURE 3 Comparison of average daily canopy transpiration between pre- and post-rainfall periods in different rainfall size classes. The error bars indicate standard deviation. Means without common letters are significantly different at $p<.05$ according to $t$ test

FIGURE 4 Relationship between $T_{c}$ and corresponding duration of rainless intervals

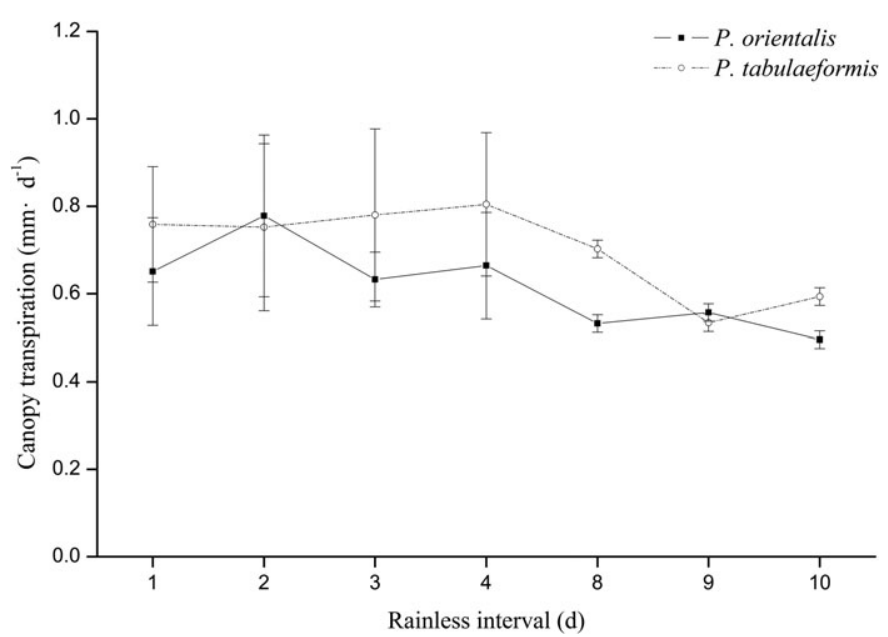




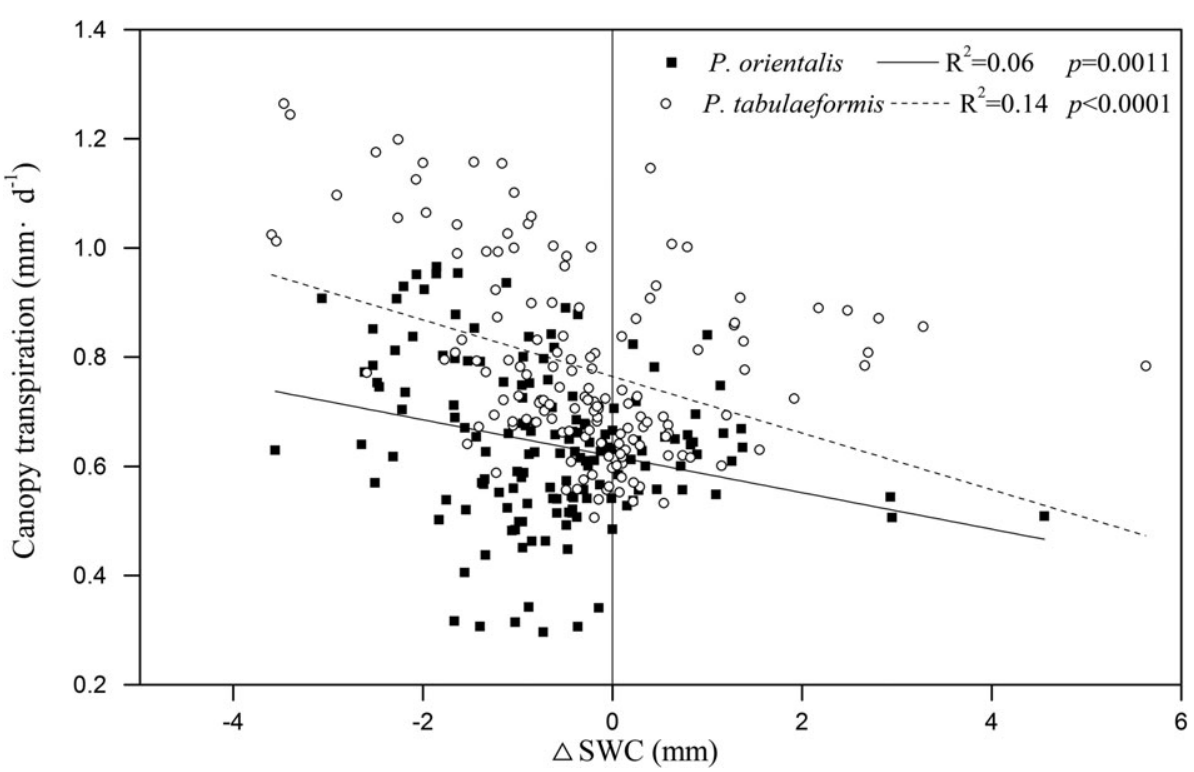

FIGURE 5 Correlation between daily $T_{c}$ and the net change in soil water content $(\triangle S W C)$

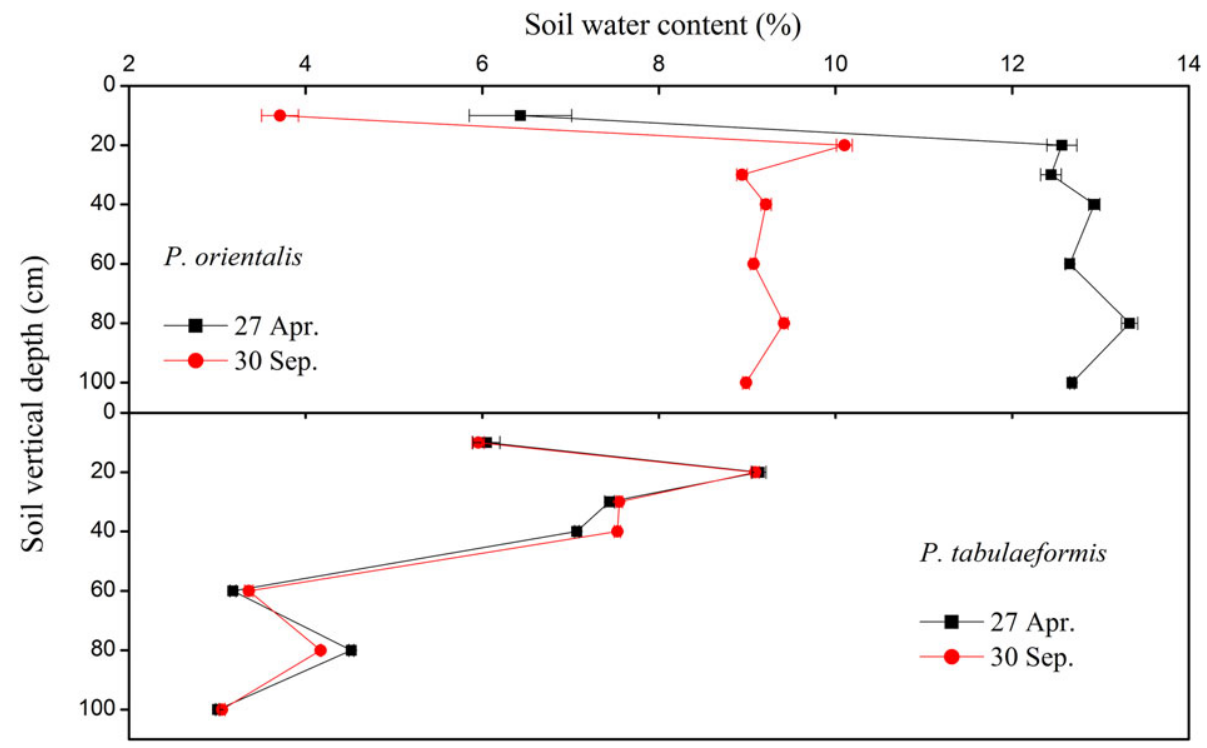

FIGURE 6 Vertical distribution of soil water content in two plots measured on April 27 and September 30, representing soil water content at the beginning and end of the growing season

TABLE 4 Monthly values of water budget calculated by observed components $(\mathrm{mm})$

\begin{tabular}{llrrrr} 
Species & Month & $\boldsymbol{P}$ & $\boldsymbol{T}_{c}$ & \multicolumn{1}{c}{$\Delta$ SWC } & $\boldsymbol{E}$ \\
\hline Platycladus orientalis & May & 71.8 & 17.97 & \multicolumn{1}{c}{4.6} & 49.03 \\
& June & 51.6 & 17.88 & -3.09 & 36.61 \\
& July & 105.2 & 23.26 & -11.02 & 92.63 \\
& August & 26.0 & 20.29 & -19.11 & 24.73 \\
& September & 41.0 & 18.55 & -1.81 & 24.11 \\
& Total & 295.6 & 97.95 & -30.43 & 227.11 \\
Pinus tabulaeformis & May & 71.8 & 27.24 & 11.78 & 32.31 \\
& June & 51.6 & 21.72 & 0.48 & 29.21 \\
& July & 105.2 & 28.76 & 8.21 & 67.61 \\
& August & 26.0 & 25.61 & -14.33 & 14.6 \\
& September & 41.0 & 19.52 & -4.37 & 25.75 \\
& Total & 295.6 & 122.85 & 1.77 & 169.48
\end{tabular}

Note. $P=$ precipitation; $T_{c}=$ canopy transpiration; $\triangle S W C=$ net change in soil water content; $E$ = evaporation. primarily variation in the stomatal regulation of transpiration, played an important role in such physiological processes. For example, Wang et al. (2009) indicated that SF responses differed significantly among Robinia pseudoacacia, P. tabulaeformis, and Cedrus deodara. In addition, stomatal sensitivity to $R_{a}$, VPD, leaf water potential, and SWC vary with time (Wang et al., 2009; Zheng \& Wang, 2014). SF of R. pseudoacacia, $P$. tabulaeformis, and $C$. deodara showed a rapid response to $R_{a}$ in the morning but began to follow the pattern of VPD in the afternoon (Wang et al., 2009). Zheng and Wang (2014) found that Haloxylon ammodendron presented a clockwise rotation between SF and VPD.

Meanwhile, plant morphology (i.e., DBH, height, and crown projected area) was another factor causing hysteresis (Wang et al., 2009). Under similar climate conditions, the longer the distance between canopy and trunk, the lower SF density was observed, 
indicating a delayed SF response (Liu, Li, \& Ma, 2008; Wang, Ma, \& Sun, 2002). Granier, Biron, and Lemoine (2000) suggested that the different SF response was probably due to the different amount of exchangeable water in tissues, and the capacitance phenomenon has been observed in coniferous species. In the present study, both $P$. orientalis and $P$. tabulaeformis clearly show nighttime SF, suggesting that stored water may also contribute to hysteresis (Figure 2). Furthermore, the nighttime flow reflects the adaptation strategy of plants to severe drought (Yin et al., 2013). As reported by Doronila and Forster (2015), the ability of a plant to maintain transpiration (SF) under high temperature and high VPD conditions allows a plant to uptake additional $\mathrm{CO}_{2}$ for a given amount of water lost, thereby enabling higher growth rates. $P$. tabulaeformis was observed to have a greater tolerance to a warmer and drier climate (Table 2), suggesting that it can effectively consume much more water. Yang, Chen, Zhu, and $\mathrm{Bi}$ (2008) indicated that in the semiarid Loess Plateau, P. tabulaeformis uses water more efficiently than R. pseudoacacia, and Malus pumila. Similar results were also found in mixed forests of different ages (Chang, Wang, Wu, Cui, \& Liu, 2013) and different species (Chen et al., 2014a; Nie, Li, \& Zhai, 2005). However, other studies reported that the same strategy appeared to be a disadvantage in some water-limited environments (Doronila \& Forster, 2015). The phenomenon can be expressed as a species-specific response to water supplementation. For example, R. pseudoacacia tends to transpire water actively as long as it is supplied (Du et al., 2011), while Quercus coccifera maintains a high daily SF rate regardless of the decline in water potential (Chirino et al., 2011), and Larix decidua maintains high transpiration rates under severe soil drought stress (Leo et al., 2014).

\subsection{The relationship between transpiration and rainfall}

Previous studies have demonstrated a relationship between the size of rainfall events and plant responses (Chen et al., 2014a; Du et al., 2011; Zeppel et al., 2008; Zhao \& Liu, 2010). For example, the increase and persistence of SF density and the time constant of the decay in transpiration after rainfall are positively correlated with the amount of precipitation (Zeppel et al., 2008). For Eucalyptus crebra and Callitris glaucophylla in eastern Australia, $20 \mathrm{~mm}$ rainfall was needed to elicit a significant increase in $T_{c}$ (Zeppel et al., 2008). The maximum SF density of R. pseudoacacia, Quercus liaotungensis, and Armeniaca sibirica generally showed an increasing trend in response to the rainfall events, and it differed in months and plant species (Du et al., 2011).

In contrast, Chen et al. (2014b) indicated that rainfall amount did not affect $T_{c}$ recovery on the event scale. $T_{c}$ recovery was significantly related to the difference between post- and pre-rainfall VPD values. Moreover, the time interval between consecutive rain events significantly affected the recovery of $T_{c}$ (i.e., $T_{c}$ declined as the interval extended). Zeppel et al. (2008) found that when antecedent soil moisture was ample or when potential evapotranspiration was low after rain, the percentage increase of post-rainfall $T_{c}$ was always small, and vice versa.

SWC and potential evapotranspiration affected the ability of roots to supply water to the canopy and that of the atmosphere to drive evaporation from the canopy (Bosch, Marshall, \& Teskey, 2014; Ungar et al., 2013; Zhang et al., 2015). Similarly, a general increase in $T_{c}$ was observed for $P$. tabulaeformis and $P$. orientalis after rainfall, but it only increased significantly when the rainfall exceeded $15 \mathrm{~mm}$ (Figure 3). Small rainfall events were not able to replenish the deep soil moisture effectively due to their ineffective infiltration and high evaporation rate. Time lags of plant response to rainfall pulses always occurred (Ogle \& Reynolds, 2004). For example, Nitraria sphaerocarpa and Elaeagnus angustifolia in the desert-oasis ecotone of China reached the maximum sap velocity about 4.17 and 5.13 days, respectively, after rainfall (Zhao \& Liu, 2010), while the hemi-parasitic species Nuytsia floribunda in southern Australia required more than 2 weeks to fully respond to rainfall events (Burgess, 2006).

In the present study, the maximum $T_{c}$ of $P$. tabulaeformis occurred about 4 days after rainfall, and that of $P$. orientalis occurred after 2 days (Figure 4). P. orientalis had a much more rapid response to rainfall events than did P. tabulaeformis. One important factor that contributes to species-specific responses to rainfall is the root distribution, which varies among species and affects the depth to which roots can reach and absorb soil water (Chen et al., 2014a). Shallow-rooted plants had higher sensitivity to SWC and respond faster to precipitation than deep-rooted ones (Fang, Zhao, \& Jian, 2016; Meinzer, James, \& Goldstein, 2004). According to our previous studies, the fine roots of $P$. tabulaeformis and $P$. orientalis are concentrated within the $0-1 \mathrm{~m}$ soil profile, and $P$. orientalis had a relatively more robust shallow root system than P. tabulaeformis (Yang et al., 2012a). Moreover, Chen et al. (2014a) indicated that the timing of the rainfall events is another important factor affecting the total amount of transpiration. Generally, large rainfall events lead to large pulses, and small events may only be able to wet the uppermost soil layers, and a large fraction of the soil water is lost by direct evaporation (Cavanaugh, Kurc, \& Scott, 2011). In semiarid areas, small rainfall accounts for a large proportion of total rainfall events and the large cumulative effect of consecutive small rainfalls were proved to be higher than the corresponding changes caused by a single large rainfall (Zhao \& Liu, 2010).

\subsection{Effects of plant species on water budget}

The plantation of woody species and shrubs is one of the main measures to restore fragile ecosystems. It has been encouraged worldwide because of its benefits, such as soil erosion control (Chen, Huang, Gong, Fu, \& Huang, 2007; Yu et al., 2015), sediment reduction (Yang et al., 2012b; Zhang, Deng, Yan, \& Shangguan, 2016), hydrological regime regulation (Jian et al., 2015a), and carbon sequestration (Jin et al., 2014). Previous studies indicated that land cover types had different effects on soil water dynamics. Wang, Ma, Zhu, and Liu (2011) found that native species are associated with higher soil moisture than exotic species, and vegetation restoration efforts that use non-native species may result in soil desiccation in the dryland Loess Plateau. Introduced vegetation decreased deep soil moisture drastically compared with farmland and native grassland (Yang et al., 2012a; Yang et al., 2014). Jian et al. (2015a) reported that in the Loess Plateau of China, P. tabulaeformis exhibited a more severe decline in SWC than did C. korshinskii, Hippophae rhamnoides, or R. pseudoacacia. As mentioned, SWC is mainly affected by rainfall amount, $T_{c}$, soil evaporation, and surface runoff. In water-limited environments, the ability of tree species to exploit soil water has a 
crucial effect on their survival. An isotopic study also found that the water proportions of different soil layers for plant uptake vary across seasons and plant species (Chen et al., 2014b).

In the present study, the annual rainfall was almost entirely consumed by evapotranspiration, and only a small amount remained for soil water recharge. SWC under P. orientalis clearly declined (by $28.4 \%$ during the growing season) because of the high evaporation and transpiration rates (Figure 6). The small crown area of $P$. orientalis ( Table 1) allowed much more light to penetrate into the ground, increasing soil temperature and thus enhancing soil evaporation, although the shade from the overstory canopy cover reduced energy input. A comparison of water budget showed that $P$. tabulaeformis plantations had a higher $T_{c} / P$ ratio $(41.6 \%$ for $P$. tabulaeformis, compared with $33.1 \%$ for $P$. orientalis) and lower $E / P$ ratio $(57.3 \%$ for P. tabulaeformis, compared with $76.8 \%$ for $P$. orientalis).

Much more water, however, was lost by evaporation than transpiration (Table 3). Raz-Yaseef, Rotenberg, and Yakir (2010) reported that mean soil evaporation measured in sun-exposed areas was double than that of shaded areas. Greater canopy coverage also increased intercepted water loss. Canopy interception can account for $10-40 \%$ of annual evapotranspiration (Chang et al., 2013; Raz-Yaseef et al., 2010), an amount that varied with canopy density (Kumagai et al., 2014), rainfall intensity (Fang, Zhao, Jian, \& Kai, 2013), and precipitation type (Li, Cai, Man, Sheng, \& Ju, 2015). Large evapotranspiration values, combined with low levels of soil water infiltration, could cause severe soil desiccation. Wei, Zhu, Zhang, Hua-Xing, and Zhu (2007) found that SWC is higher at the early stage of tree plantation than at the late stage. The soil water in a C. korshinskii plantation was nearly balanced at the beginning of the growing season and gradually turned to be in a deficit (Jian, Zhao, Fang, \& Yu, 2015b).

Stand age and density are important factors affecting $T_{c} . T_{c}$ declined with stand age in Norway spruce (Picea abies) from 40 to 140 years (Alsheimer, Köstner, Falge, \& Tenhunen, 1998), boreal black spruce (Picea mariana) from 71 to 151 years (Ewers, Gower, BondLamberty, \& Wang, 2005), and ponderosa pine (Pinus ponderosa) from 25 to 250 years (Irvine et al., 2004). Moreover, stand density decreased with increasing stand age due to the decline in SWC (Alsheimer et al., 1998). However, Chang et al. (2013) indicated that there was no significant difference in total evapotranspiration and total water output between middle-aged (average 22 years) and mature (average 58 years) P. tabulaeformis forests. This result can be explained by the long-term cumulative effects of $T_{c}$ and the plants' physiological regulation, which result in nonsignificant differences over a short term. In the present study, $P$. orientalis and $P$. tabulaeformis were planted in 1984 and 1972, respectively, and were aged around 40 years. P. tabulaeformis showed better growth (higher plant height, larger $\mathrm{DBH}$, and greater crown area) than $P$. orientalis (Table 1 ), with a relatively lower SWC (Figure 6). Under specific climate conditions, evapotranspiration was a conservative process (Caldeira et al., 2015; Kumagai et al., 2014). Differences in stand status and plant composition mainly affect the aspects of evapotranspiration (e.g., soil evaporation, $T_{c}$, canopy interception), but not its magnitude (Chang et al., 2013; Granier et al., 2000; Kumagai et al., 2014). Therefore, in the semiarid Loess Plateau, it is critical to increase productive water loss and reduce unproductive water loss (Wang et al., 2012).

\section{5 | CONCLUSIONS}

In the present study, we mainly examined the characteristics of $T_{c}$ of $P$. orientalis and $P$. tabulaeformis with regard to water balance during the growing season in China's dryland Loess Plateau. SF of the two species showed a similar diurnal variation, but the flow varied explicitly in peak time and the corresponding optimal climate variations. Compared with $P$. orientalis, $P$. tabulaeformis showed a greater tolerance to warmer and drier climates. Both P. orientalis and P. tabulaeformis increased $T_{c}$ after rainfall due to the alleviation of water stress, although the responses were species-specific. After rainfall, $P$. orientalis showed a rapid response and reached the maximum transpiration in 2 days, while $P$. tabulaeformis reached the maximum about 2 days later. During the growing season, much more attenuation of SWC occurred in the $P$. orientalis site. Compared with the $P$. tabulaeformis plantation, 20.3\% lower $T_{c}$ was observed at the $P$. orientalis plantation, and $34.0 \%$ more water loss caused by evaporation was observed at the $P$. orientalis plantation. These findings indicated that $P$. tabulaeformis had a relatively higher productive water loss; however, this amount was still much lower than the unproductive water loss.

Our study suggests that a combined plantation of $P$. orientalis and $P$. tabulaeformis is an optimal approach. The higher and denser canopy of $P$. tabulaeformis can reduce the soil evaporation, while the lower and smaller canopy of $P$. orientalis can compensate for water loss caused by interception, thus promoting more sustainable use of water.

\section{ACKNOWLEDGMENT}

The authors acknowledge the support of the National Natural Science Foundation of China (41371123, 41390462, 41401209), the National Key Research and Development Program of China (2016YFC0501701), and the National Advanced Project of the Twelfth Five-year Plan of China (2015BAC01B02).

\section{REFERENCES}

Alsheimer, M., Köstner, B., Falge, E., \& Tenhunen, J. D. (1998). Temporal and spatial variation in transpiration of Norway spruce stands within a forested catchment of the Fichtelgebirge, Germany. Annales Des Sciences Forestières, 55, 103-123.

Bosch, D. D., Marshall, L. K., \& Teskey, R. (2014). Forest transpiration from sap flux density measurements in a Southeastern Coastal Plain riparian buffer system. Agricultural and Forest Meteorology, 187, 72-82. doi:10.1016/j.agrformet.2013.12.002

Burgess, S. S. O. (2006). Measuring transpiration responses to summer precipitation in a Mediterranean climate: A simple screening tool for identifying plant water-use strategies. Physiol Plantarum, 127, 404-412. doi:10.1111/j.1399-3054.2006.00669.x

Caldeira, M. C., Lecomte, X., David, T. S., Pinto, J. G., Bugalho, M. N., \& Werner, C. (2015). Synergy of extreme drought and shrub invasion reduce ecosystem functioning and resilience in water-limited climates. Scientific Reports, 5.

Cavanaugh, M. L., Kurc, S. A., \& Scott, R. L. (2011). Evapotranspiration partitioning in semiarid shrubland ecosystems: A two-site evaluation of soil moisture control on transpiration. Ecohydrology, 4, 671-681. doi:10.1002/eco.157

Chang, J., Wang, Q., Wu, X., Cui, L., \& Liu, S. (2013). Water balance of different age Pinus tabulaeformis forests in Taihang Mountain, Shanxi. Scientia Silvae Sinicae, 49, 1-9.

Chang, X., Zhao, W., Liu, H., Wei, X., Liu, B., \& He, Z. (2014a). Qinghai spruce (Picea crassifolia) forest transpiration and canopy conductance 
in the upper Heihe River Basin of arid northwestern China. Agricultural and Forest Meteorology, 198-199, 209-220. doi:10.1016/j. agrformet.2014.08.015

Chang, X. X., Zhao, W. Z., \& He, Z. B. (2014b). Radial pattern of sap flow and response to microclimate and soil moisture in Qinghai spruce (Picea crassifolia) in the upper Heihe River Basin of arid northwestern China. Agricultural and Forest Meteorology, 187, 14-21. doi:10.1016/j. agrformet.2013.11.004

Chen, H. S., Shao, M. G., \& Li, Y. Y. (2008). Soil desiccation in the Loess Plateau of China. Geoderma, 143, 91-100. doi:10.1016/j. geoderma.2007.10.013

Chen, L., Huang, Z., Gong, J., Fu, B., \& Huang, Y. (2007). The effect of land cover/vegetation on soil water dynamic in the hilly area of the loess plateau, China. CATENA, 70, 200-208. doi:10.1016/j. catena.2006.08.007

Chen, L., Wang, J., Wei, W., Fu, B., \& Wu, D. (2010). Effects of landscape restoration on soil water storage and water use in the Loess Plateau Region, China. Forest Ecology and Management, 259, 1291-1298. doi:10.1016/j.foreco.2009.10.025

Chen, L., Zhang, Z., Zeppel, M., Liu, C., Guo, J., Zhu, J., ... Zha, T. (2014a). Response of transpiration to rain pulses for two tree species in a semiarid plantation. Int J Biometeorol, 58, 1569-1581. doi:10.1007/s00484013-0761-9

Chen, L. X., Zhang, Z. Q., Zha, T. G., Mo, K. L., Zhang, Y., \& Fang, X. R. (2014b). Soil water affects transpiration response to rainfall and vapor pressure deficit in poplar plantation. New Forest, 45, 235-250. doi:10.1007/s11056-014-9405-0

Chen, Y. J., Cao, K. F., Schnitzer, S. A., Fan, Z. X., Zhang, J. L., \& Bongers, F. (2015). Water-use advantage for lianas over trees in tropical seasonal forests. New Phytol, 205, 128-136. doi:10.1111/Nph.13036

Chirino, E., Bellot, J., \& Sanchez, J. R. (2011). Daily sap flow rate as an indicator of drought avoidance mechanisms in five Mediterranean perennial species in semi-arid southeastern Spain. Trees-Structure and Function, 25, 593-606. doi:10.1007/s00468-010-0536-4

de Dios, V. R., Roy, J., Ferrio, J. P., Alday, J. G., Landais, D., Milcu, A., \& Gessler, A. (2014). Processes driving nocturnal transpiration and implications for estimating land evapotranspiration. Scientific Reports, 5

Doronila, A. I., \& Forster, M. A. (2015). Performance measurement via sap flow monitoring of three Eucalyptus species for mine site and dryland salinity phytoremediation. International Journal of Phytoremediation, 17, 101-108. doi:10.1080/15226514.2013.850466

Du, S., Wang, Y.-L., Kume, T., Zhang, J.-G., Otsuki, K., Yamanaka, N., \& Liu, G.-B. (2011). Sapflow characteristics and climatic responses in three forest species in the semiarid Loess Plateau region of China. Agricultural and Forest Meteorology, 151, 1-10.

Ewers, B. E., Gower, S. T., Bond-Lamberty, B., \& Wang, C. K. (2005). Effects of stand age and tree species on canopy transpiration and average stomatal conductance of boreal forests. Plant Cell \& Environment, 28, 660-678.

Fang, S. M., Zhao, C. Y., Jian, S. Q., \& Kai, Y. U. (2013). Canopy interception of Pinus tabulaeformis plantation on Longzhong Loess Plateau, Northwest China:Characteristics and simulation. Chinese Journal of Applied Ecology, 24, 1509-1516.

Fang, S. M., Zhao, C. Y., \& Jian, S. Q. (2016). Canopy transpiration of Pinus tabulaeformis plantation forest in the Loess Plateau region of China. Environmental Earth Sciences, 75. doi:10.1007/S12665-016-5291-4

Fu, B.-J., Zhang, Q.-J., Chen, L.-D., Zhao, W.-W., Gulinck, H., Liu, G.-B., ... Zhu, Y.-G. (2006). Temporal change in land use and its relationship to slope degree and soil type in a small catchment on the Loess Plateau of China. CATENA, 65, 41-48. doi:10.1016/j.catena.2005.07.005

Gotsch, S. G., Crausbay, S. D., Giambelluca, T. W., Weintraub, A. E., Longman, R. J., Asbjornsen, H., ... Dawson, T. E. (2014). Water relations and microclimate around the upper limit of a cloud forest in Maui, Hawai'i. Tree Physiology, 34, 766-777. doi:10.1093/treephys/tpu050

Granier, A. (1987). Evaluation of transpiration in a Douglas-fir stand by means of sap flow measurements. Tree physiology, 3, 309-320.
Granier, A., Biron, P., \& Lemoine, D. (2000). Water balance, transpiration and canopy conductance in two beech stands. Agricultural and Forest Meteorology, 100, 291-308. doi:10.1016/S0168-1923(99)00151-3

Irvine, J., Law, B. E., Kurpius, M. R., Anthoni, P. M., Moore, D., \& Schwarz, P. A. (2004). Age-related changes in ecosystem structure and function and effects on water and carbon exchange in ponderosa pine. Tree Physiology, 24, 753-763.

Jian, S., Zhao, C., Fang, S., \& Yu, K. (2015a). Effects of different vegetation restoration on soil water storage and water balance in the Chinese Loess Plateau. Agricultural and Forest Meteorology, 206, 85-96. doi:10.1016/j.agrformet.2015.03.009

Jian, S. Q., Zhao, C. Y., Fang, S. M., \& Yu, K. (2015b). Evaluation of water use of Caragana korshinskii and Hippophae rhamnoides in the Chinese Loess Plateau. Canadian Journal of Forest Research, 45, 15-25. doi:10.1139/ cjfr-2014-0219

Jin, Z., Dong, Y., Wang, Y., Wei, X., Wang, Y., Cui, B., \& Zhou, W. (2014). Natural vegetation restoration is more beneficial to soil surface organic and inorganic carbon sequestration than tree plantation on the Loess Plateau of China. Sci Total Environ, 485, 615-623. doi:10.1016/j. scitotenv.2014.03.105

Kumagai, T., Tateishi, M., Miyazawa, Y., Kobayashi, M., Yoshifuji, N., Komatsu, H., \& Shimizu, T. (2014). Estimation of annual forest evapotranspiration from a coniferous plantation watershed in Japan (1): Water use components in Japanese cedar stands. J Hydrol, 508, 66-76. doi:10.1016/j. jhydrol.2013.10.047

Leo, M., Oberhuber, W., Schuster, R., Grams, T. E. E., Matyssek, R., \& Wieser, G. (2014). Evaluating the effect of plant water availability on inner alpine coniferous trees based on sap flow measurements. Eur J Forest Res, 133, 691-698. doi:10.1007/s10342-013-0697-y

Li, Y., Cai, T. J., Man, X. L., Sheng, H. C., \& Ju, C. Y. (2015). Canopy interception loss in a Pinus sylvestris var. mongolica forest of Northeast China. Journal of Arid Land, 7, 831-840. doi:10.1007/s40333-015-0013-4

Liu, D., Li, J., \& Ma, D. (2008). Spatial variation pattern of Platycladus orientalis stem sap flow. Chinese Journal of Ecology, 27, 1262-1268.

Liu, W., Zhang, X. C., Dang, T., Ouyang, Z., Li, Z., Wang, J., ... Gao, C. (2010). Soil water dynamics and deep soil recharge in a record wet year in the southern Loess Plateau of China. Agricultural Water Management, 97, 1133-1138. doi:10.1016/j.agwat.2010.01.001

Meinzer, F. C., James, S. A., \& Goldstein, G. (2004). Dynamics of transpiration, sap flow and use of stored water in tropical forest canopy trees. Tree physiology, 24, 901-909.

Mitchell, P. J., Veneklaas, E., Lambers, H., \& Burgess, S. S. O. (2009). Partitioning of evapotranspiration in a semi-arid eucalypt woodland in south-western Australia. Agricultural and Forest Meteorology, 149, 25-37. doi:10.1016/j.agrformet.2008.07.008

Nie, L., Li, J., \& Zhai, H. (2005). Study of the rate of stem sap flow in Pinus tabulaeformis and Quercus variabilis by using the TDP method. Acta Ecologica Sinica, 25, 1934-1940.

Ogle, K., \& Reynolds, J. F. (2004). Plant responses to precipitation in desert ecosystems: Integrating functional types, pulses, thresholds, and delays. Oecologia, 141, 282-294.

Raz-Yaseef, N., Rotenberg, E., \& Yakir, D. (2010). Effects of spatial variations in soil evaporation caused by tree shading on water flux partitioning in a semi-arid pine forest. Agricultural and Forest Meteorology, 150, 454-462.

Roddy, A., \& Dawson, T. (2013). Novel patterns of hysteresis in the response of leaf-level sap flow to vapor pressure deficit. IX International Workshop on Sap Flow, 991, 261-267.

Rodríguez-Caballero, E., Cantón, Y., Chamizo, S., Afana, A., \& Solé-Benet, A. (2012). Effects of biological soil crusts on surface roughness and implications for runoff and erosion. Geomorphology, 145-146, 81-89.

Rodriguez-Dominguez, C. M., Ehrenberger, W., Sann, C., Rüger, S. Sukhorukov, V., Martín-Palomo, M. J., ... Fernández, J. E. (2012). Concomitant measurements of stem sap flow and leaf turgor pressure in olive trees using the leaf patch clamp pressure probe. 
Agricultural Water Management, 114, 50-58. doi:10.1016/j. agwat.2012.07.007

Shen, Q., Gao, G., Fu, B., \& Lü, Y. (2015). Responses of shelterbelt stand transpiration to drought and groundwater variations in an arid inland river basin of Northwest China. J Hydrol, 531, 738-748. doi:10.1016/ j.jhydrol.2015.10.053

Ungar, E. D., Rotenberg, E., Raz-Yaseef, N., Cohen, S., Yakir, D., \& Schiller, G. (2013). Transpiration and annual water balance of Aleppo pine in a semiarid region: Implications for forest management. Forest Ecology and Management, 298, 39-51. doi:10.1016/j.foreco.2013.03.003

Wang, H., Ma, L., \& Sun, P. (2002). Sap flow fluctuations of Pinus tabulaeformis and Platycladus orientalis in late autumn. Scientia Silvae Sinicae, 38, 31-37.

Wang, H., Ouyang, Z. Y., Zheng, H., Wang, X. K., Ni, Y. M., \& Ren, Y. F. (2009). Time lag characteristics of stem sap flow of common tree species during their growth season in Beijing downtown. Ying yong sheng tai $x$ ue bao = The journal of applied ecology / Zhongguo sheng tai xue xue hui. Zhongguo ke xue yuan Shenyang ying yong sheng tai yan jiu suo zhu ban, 20, 2111-2117.

Wang, L., D'Odorico, P., Evans, J. P., Eldridge, D. J., Mccabe, M. F., Caylor, K. K., \& King, E. G. (2012). Dryland ecohydrology and climate change: Critical issues and technical advances. Hydrology \& Earth System Sciences, 16, 2585-2603.

Wang, X. C., Muhammad, T. N., Hao, M. D., \& Li, J. (2011a). Sustainable recovery of soil desiccation in semi-humid region on the Loess Plateau. Agricultural Water Management, 98, 1262-1270. doi:10.1016/j. agwat.2011.03.007

Wang, Y., Ma, S., Zhu, Y., \& Liu, Z. (2011). Impacts of land use and plant characteristics on dried soil layers in different climatic regions on the Loess Plateau of China. Agricultural and Forest Meteorology, 151, 437-448. doi:10.1016/j.agrformet.2010.11.016

Wei, T., Zhu, J. Z., Zhang, J. J., Hua-Xing, B. I., \& Zhu, Q. K. (2007). Protective forest system at small watershed in the gullied-hilly loess area based on water balance on the Loess Plateau. Research of Soil \& Water Conservation, 14, 179-183.

Yang, F., Chen, L., Zhu, Q., \& Bi, H. (2008). Analysis of water consumption of main afforestation species in western Shanxi of Loess Plateau. Research of Soil and Water Conservation, 15, 41-45.

Yang, L., Wei, W., Chen, L., Jia, F., \& Mo, B. (2012a). Spatial variations of shallow and deep soil moisture in the semi-arid Loess Plateau, China. Hydrol Earth Syst Sc, 16, 3199-3217. doi:10.5194/hess-16-3199-2012

Yang, L., Wei, W., Chen, L. D., \& Mo, B. R. (2012b). Response of deep soil moisture to land use and afforestation in the semi-arid Loess Plateau, China. J Hydrol, 475, 111-122. doi:10.1016/j.jhydrol.2012.09.041

Yang, L., Wei, W., Chen, L. D., Chen, W. L., \& Wang, J. L. (2014). Response of temporal variation of soil moisture to vegetation restoration in semi- arid Loess Plateau, China. Catena, 115, 123-133. doi:10.1016/j. catena.2013.12.005

Yang, L., Chen, L. D., \& Wei, W. (2015). Effects of vegetation restoration on the spatial distribution of soil moisture at the hillslope scale in semi-arid regions. Catena, 124, 138-146. doi:10.1016/j.catena.2014.09.014

Yaseef, N. R., Yakir, D., Rotenberg, E., Schiller, G., \& Cohen, S. (2010). Ecohydrology of a semi-arid forest: Partitioning among water balance components and its implications for predicted precipitation changes. Ecohydrology, 3, 143-154. doi:10.1002/Eco.65

Yin, L.-H., Huang, J.-T., Wang, X.-Y., Dong, J.-Q., Hong-Yun, M.-A., \& Zhang, J. (2013). Characteristics of night time sap flow of Salix matsudana and Populus simonii in Yulin, Shaanxi. Journal of Northwest A \& F University, 41, 85-90.

Yu, Y., Wei, W., Chen, L. D., Jia, F. Y., Yang, L., Zhang, H. D., \& Feng, T. J. (2015). Responses of vertical soil moisture to rainfall pulses and land uses in a typical loess hilly area, China. Solid Earth, 6, 595-608. doi:10.5194/se-6-595-2015

Zeppel, M., Macinnis-Ng, C. M., Ford, C. R., \& Eamus, D. (2008). The response of sap flow to pulses of rain in a temperate Australian woodland. Plant and soil, 305, 121-130.

Zhang, B., He, C., Burnham, M., \& Zhang, L. (2016). Evaluating the coupling effects of climate aridity and vegetation restoration on soil erosion over the Loess Plateau in China. Sci Total Environ, 539, 436-449. doi:10.1016/j.scitotenv.2015.08.132

Zhang, J.-G., Guan, J.-H., Shi, W.-Y., Yamanaka, N., \& Du, S. (2015). Interannual variation in stand transpiration estimated by sap flow measurement in a semi-arid black locust plantation, Loess Plateau, China. Ecohydrology, 8, 137-147. doi:10.1002/eco.1495

Zhang, Y.-w., Deng, L., Yan, W.-m., \& Shangguan, Z.-p. (2016). Interaction of soil water storage dynamics and long-term natural vegetation succession on the Loess Plateau, China. CATENA, 137, 52-60. doi:10.1016/j. catena.2015.08.016

Zhao, W., \& Liu, B. (2010). The response of sap flow in shrubs to rainfall pulses in the desert region of China. Agricultural and forest meteorology, 150, 1297-1306.

Zheng, C. L., \& Wang, Q. (2014). Water-use response to climate factors at whole tree and branch scale for a dominant desert species in central Asia: Haloxylon ammodendron. Ecohydrology, 7, 56-63. doi:10.1002/Eco.1321

How to cite this article: Zhang H, Wei W, Chen L, Yang L. Evaluating canopy transpiration and water use of two typical planted tree species in the dryland Loess Plateau of China. Ecohydrology. 2017;10:e1830. https://doi.org/10.1002/eco.1830 